Revista Iberoamericana, Vol. LXXVIII, Núms. 238-239, Enero-Junio 2012, 147-161

\title{
LA INVENCIÓN DEL FUTURO. LIMA Y LA DIMENSIÓN DISTÓPICA EN MAÑANA, LAS RATAS, DE JOSÉ B. ADOLPH
}

POR

Giancarlo Stagnaro

Tulane University

La literatura peruana contemporánea mantiene una deuda pendiente con José B. Adolph. No obstante de ser uno de los escritores peruanos más prolíficos del siglo xx y en diversos registros literarios -honor que podría disputar con Mario Vargas Llosa, por ejemplo-, la presencia de Adolph dentro del establishment literario local suele ser tomada con aprecio por el carisma que generaba en lo personal, pero soslayada en lo concerniente a la valoración literaria en sí. Últimamente, estos vacíos han venido siendo subsanados por jóvenes críticos literarios muy interesados en trazar una historia y una periodización de la ciencia ficción en el Perú.

José Bernardo Adolph nació en Stuttgart (Alemania) en 1933. Cinco años más tarde su familia viajó y se instaló en el Perú, debido a la situación política en el país europeo. Su carrera periodística se consolidó entre las décadas de 1960 y 1970, cuando incursiona en la producción de cuentos y teatro. Adolph es autor de los libros de relatos El retorno de Aladino (Lima, 1968); Hasta que la muerte (Lima, 1971); Invisible para las fieras (Lima, 1972); Cuentos del relojero abominable (Lima, 1973); Mañana fuimos felices (Lima, 1974); La batalla del café (Lima, 1984); Un dulce horror (Lima, 1989); Diario del sótano (Lima, 1996); Los fines del mundo (2002), y Es sólo un viejo tren (2007).

Adolph también publicó las novelas La ronda de los generales (1974), una punzante sátira del militarismo peruano; Mañana, las ratas (1984), que se ambienta en el Perú del siglo xxi; Dora (1989), un retrato de la luchadora social germano-peruana, Dora Mayer de Zulen; la trilogía novelística De mujeres y heridas, compuesta por Ningún Dios, Especulaciones sobre otro barco y La profunda maldad del universo; y dos de sus últimos libros, escritos en clave satírica, como La verdad sobre Dios y JBA (2001) y Un ejército de locos (2003). El escritor falleció en Lima en febrero de 2008.

Toda esta vasta producción literaria, que pudiera atraer la atención de lectores y académicos, aún no ha sido lo suficientemente apreciada y evaluada en su justa dimensión. Esto tiene que ver en gran parte con la tendencia conservadora que predomina en el campo literario peruano, que por lo general mantiene su distancia frente a las 
representaciones que no caben dentro del realismo predominante. Lo paradójico es que, en el caso de Adolph, su literatura nunca abandonó la realidad (quizás porque, como él mismo dice en tono irónico, ésta no existe y no había nada que abandonar ${ }^{1}$ ). Al contrario, su obra, al ubicarse en diversos géneros, se sitúa en la misma línea de modernización literaria que propugnaron en su momento César Vallejo, José Carlos Mariátegui, Emilio Adolfo Westphalen, Jorge Eduardo Eielson, Mario Vargas Llosa y Julio Ramón Ribeyro, entre otros.

Mañana, las ratas es una de las pocas novelas de anticipación de la literatura peruana. Su protagonista, Tony Tréveris, es un funcionario regional del Directorio Suprema, una enorme corporación transnacional que engloba el poder político y económico en Occidente. Tréveris sale de su casa, ubicada al sur de Lima, el 18 de enero de 2034, ${ }^{2}$ rumbo a las oficinas del Directorio Regional, filial de la empresa Stimudrinks, ubicadas en el antiguo centro histórico de la ciudad. Dicha corporación capitalista viene enfrentando la amenaza de una sublevación encabezada por católicos ortodoxos (conocidos como cat-ox), de inspiración lefebvrista ${ }^{3}$ y liderados por el misterioso Cardenal Negro. Mientras el Directorio regional busca reprimir la sublevación con un poderoso arsenal tecnológico, Tréveris recibe, atiende e inicia una apasionada relación con Linda King, enviada del Directorio Supremo.

Pero la misión de King es otra: llegar a un acuerdo político con los cat-ox, a expensas de las sospechas de Tréveris. Los cat-ox buscan hacerse del poder por medios violentos, en un intento de aglutinar a los pobres y desplazados del Tercer Mundo, o "ratas", como se les conoce despectivamente en las altas esferas del poder del Directorio Regional. Es la gente que quedó fuera del nuevo sistema económico, viviendo en el desamparo total. De este modo, Tréveris y King confrontan sus decisiones en un entorno disímil al de sus creencias y lealtades.

La recepción crítica de Mañana, las ratas ha sido de lo más diversa. Elton Honores (2008) ha revisado los principales aportes y comentarios de la crítica en relación con esta novela. Entre ellos, figura el artículo "Mañana, las ratas... Lima la horrible del siglo

1 Dice Adolph, citado por Nevares: "No hay realidad nacional. Sólo fenómenos. La física subatómica de hoy en día llega a la misma conclusión que los hindúes hace 5,000 años: toda realidad es ilusión, maya".

2 La fundación hispánica de Lima data del 18 de enero de 1535. Originalmente denominada la Ciudad de los Reyes, Lima adquiere su nombre del topónimo del río circundante, Rímac, palabra quechua que significa "el que habla".

3 Marcel Lefebvre (1905-1991) fue un arzobispo francés que realizó la mayor parte de su carrera en África. Fue el líder de la oposición a las reformas planteadas por el concilio Vaticano II. En 1988, Lefebvre consagró a cuatro obispos en abierta desobediencia al canon de la Santa Sede, por lo que fueron excomulgados tanto él como los obispos. En la historia eclesiástica del siglo xx es una figura altamente polémica, dado que reivindicó la actuación de la Iglesia católica durante la ocupación nazi en Francia (1940-1944) y apoyó públicamente a los regímenes de Franco (España), Videla (Argentina) y Pinochet (Chile).

Revista Iberoamericana, Vol. LXXVIII, Núms. 238-239, Enero-Junio 2012, $147-161$
ISSN 0034-9631 (Impreso) 
xxı”. Nos interesa, en este caso, y a partir del título de dicho artículo, la asociación que se puede establecer entre la novela de Adolph y un ensayo canónico como el del escritor peruano Sebastián Salazar Bondy (escritor de la generación precedente a la de Adolph). Pero sobre todo porque ambos tienen en común una estrategia de develación de nuestros presupuestos de la realidad. Para Salazar Bondy el fracaso de la articulación de Lima como ciudad tiene que ver con el fracaso del Perú en sus intentos de modernización. A su vez, para Adolph el fracaso de la utopía capitalista en países como el Perú posee varios matices extrapolados de Salazar Bondy, a lo cual se añade un factor no menos decisivo del Perú de fines del siglo xx: la violencia política, que ya resultaba real y visible en la época en que fue publicada esta novela. En todo caso, nos interesa encontrar puntos comunes por el giro distópico (Moylan 172) que subyace en ambas escrituras.

\section{CORRESPONDENCIAS}

El discurso utópico marca el derrotero conceptual de la modernidad. Desde que el término fuera acuñado por Moro, las utopías son discursos que articulan los efectos de la Revolución Industrial y capitalista en torno a nociones como progreso y bienestar. La utopía instala un espacio de hallazgo en el cual es posible planear y pensar el futuro en función de la superación del presente:

That discovery may now be seen as part of what may in the largest sense be called the bourgeois cultural revolution, the process whereby the definitive establishment of a properly capitalist mode of production as it were reprograms and utterly restructures the values, life rhythms, cultural habits, and temporal sense of its subjects. Capitalism demands in this sense a different experience of temporality from that which was appropriate to a feudal or tribal system, to the polis or to the forbidden city of the sacred despot: it demands a memory of qualitative social change, a concrete vision of the past which we may expect to find completed by that far more abstract and empty conception of some future terminus which we sometimes call "progress”. (Jameson 149)

El capitalismo, en ese sentido, ha reestructurado tanto el ámbito social como el subjetivo. Esta nueva percepción del cambio histórico y de la realidad misma permite la emergencia de un tipo de memoria que es capaz de abordar tanto el pasado y, al hacerlo (como lo hace la novela histórica, dice Jameson), también abre la posibilidad de elaborar un ideal posible y realizable sobre el futuro. Aquí surge la visión utópica y la ciencia ficción como género literario que permite la asimilación de los cambios, en una época como el siglo xix, que vivía una comprobada efervescencia por las posibilidades enormes de los cambios tecnológicos.

El nudo del discurso utópico abarca la proyección un futuro ficcional “[...] from which it defamiliarizes the present state of society and reconceives it as an objective

\footnotetext{
Revista Iberoamericana, Vol. LXXVIII, Núms. 238-239, Enero-Junio 2012, 147-161 
historical totality rather than a subjective way of life. In utopia, the present is the past of a specific, fictional future” (Beaumont 38-39). La “desfamiliarización” es una característica operativa que tiene en común tanto discursos utópicos como distópicos; muestra el estado actual de manera reconocible, pero que proyectado hacia el futuro ya no nos parece del todo "familiar", al mostrarse en toda su extensión: lo que es expuesto en el plano del deseo, el anhelo o la proyección imaginaria alcanza su concreción tangible. En ese sentido, autores como M. Keith Booker sostienen que utopía y distopía no son nociones del todo diametralmente opuestas.

Not only is one man's utopia another man's dystopia, but utopian visions of an ideal society often inherently suggests a criticism of the current order of things as nonideal, while dystopian warnings of the dangers of "bad" utopias still allow for the possibility of "good" utopias, especially since dystopian societies are generally more or less thinly veiled refigurations or a situation that already exists in reality. (15)

Utopía y distopía se corresponden. La utopía se manifiesta en función del deseo de cambiar el presente (cuando se reúnen el principio del placer y el principio del presente, según Freud); y la distopía nos alerta sobre las consecuencias de la materialización de ese deseo en la medida de las reconfiguraciones de situaciones condicionantes del presente.

La aparición del discurso distópico tiene que ver con los principales cambios históricos, sociales y culturales del siglo xx. La concepción decimonónica del progreso entra en crisis en los primeros años del siglo y se acentúa con las guerras mundiales. 1984, de Orwell, y A Brave New World, de Huxley, dan la alerta sobre las amenazas totalitarias que se ciernen sobre la humanidad: la primera es una distopía represiva que anula la subjetividad; mientras que en la segunda el hedonismo y el individualismo son representados como formas de control social.

En contraposición a las distopías “clásicas”, Moylan contrapone otro tipo de sensibilidad distópica en los años posteriores a la Segunda Guerra Mundial. En ese sentido, los "nuevos mapas del infierno" se hallan inmersas en la cultura de masas y no hurgan necesariamente en el pasado para evocar tiempos mejores: "Nor did they easily look ahead to a utopian future. A work in the belly of the beast, they focused more often on experiences of everyday life in societies increasingly shaped by a refined imbrication of economy and culture" (182).

Nos interesa, para las consideraciones de la novela de Adolph, esta "imbricación refinada" entre economía y cultura que afecta a los países latinoamericanas en una dimensión distinta al resto de países occidentales. La aparición de esta sensibilidad distópica más reciente ya no ofrece distinciones entre el anhelo y la realidad porque esa distinción sencillamente se ha vuelto más nebulosa en la última mitad del siglo xx. Esa borrosidad es la que ha hecho posible la aparición de particulares visiones, como

Revista Iberoamericana, Vol. LXXVIII, Núms. 238-239, Enero-Junio 2012, $147-161$
ISSN 0034-9631 (Impreso) 
las de Philip K. Dick, que son al mismo tiempo muy aclamadas por la cultura de masas contemporánea.

UTOPÍA Y CIUDAD

No es por demás recordar que el discurso utópico surge con el descubrimiento del Continente. Las crónicas y relatos de la conquista y colonización del “nuevo mundo” (y habrá que resaltar aquí el adjetivo como posibilidad abierta de un mundo distinto y, por qué no, mejor) incendiaron la imaginación europea. Por ejemplo, es posible rastrear una posible genealogía de la utopía desde textos como los Comentarios reales del Inca Garcilaso de la Vega en el pensamiento europeo de los siglos XVIII y XIX.

La utopía también será el paradigma del modelo instalado en las jóvenes repúblicas, al calor de las guerras de independencia. El historiador peruano Jorge Basadre habla de la "promesa republicana” en el sentido de que la causa independentista se basó en los ideales utópicos de una sociedad mejor, integral, plena. Este gesto no atacaba la razón colonial, sino que terminaba reproduciendo la proyección utópica instaurada por los colonizadores. Se terminó asumiendo el proyecto republicano en términos de la dicotomía entre civilización y barbarie (Sarmiento y otros). El aspecto utópico, promovido por las elites republicanas y criollas (herederas en línea directa de las elites coloniales), proviene del impulso civilizatorio europeo.

En un primer momento, la ciencia ficción en América Latina se ha movido desde el lado de lo utópico, de la promesa, la modernización y el progreso. El caso peruano no ha sido ajeno a esta problemática, plausible si consideramos el nivel del debate político en el siglo xix. Tal es el caso de la novela de folletín Lima de aquí a cien años (en el diario El Comercio, 1843-1844), de Julián M. Portillo (1818-1862), que describe dos visiones de la modernidad -tanto la planteada tanto desde Lima (francesa e inglesa) como desde el Cusco (con mixturas andinas). ${ }^{4}$ En el momento de enunciación del relato, Lima y el Cusco se hallaban, al menos en los primeros decenios del siglo XIX, en una suerte de rivalidad por la representación de la nación.

Quizás el último de los discursos utópicos latinoamericanos sea la revolución, vinculada a los movimientos de las décadas de 1950 y 1960, que prolongan de alguna manera la continuidad en la “liberación” propalada por los independentistas. No obstante, desde el izquierdismo más radical hasta la teología de la liberación, estos proyectos alcanzan el cénit y luego entran en caída libre. En esos territorios, en estos cambios de ánimo social, es que se instala la distopía entre los escritores latinoamericanos.

4 Sobre esta novela, pueden consultarse los trabajos de Bernal y Villalonga ("Siglo y medio de silencio”), Bonifaz (“Compilador”) y Elguera "Diálogo”.

ISSN 0034-9631 (Impreso) 


\begin{abstract}
Aunque distopía y utopía comparten el empleo de la realidad extratextual como punto de partida para la constitución de sus universos narrativos, la primera no se propone como una alternativa, sino como el resultado de ciertas tendencias que predominan en el presente. En otros términos, se postula la idea de un futuro diferente del presente, pero conectado lógicamente a él por el desarrollo de las circunstancias actuales. Como consecuencia, una distopía afirma los principios de continuidad y, con cierto tono admonitorio, enfatiza el carácter indeseable del mundo proyectado. El resultado de esta concepción es que las catástrofes naturales, la instauración de gobiernos absolutistas, la deshumanización de las relaciones sociales, la agudización de las confrontaciones genéricas y las guerras civiles [...] aparecen como agudización de las circunstancias en las que se desenvuelven los países hispanoamericanos en la década de 1970. (Cano 255)
\end{abstract}

La distopía, al menos en el caso latinoamericano, se corresponde con el momento de la crisis. Las generaciones posteriores al centenario de la independencia hacen sentir su voz crítica a los modelos modernizadores y a las consecuencias que éstos viene generando al conjunto de la sociedad. Se forja el panorama latinoamericano como Tercer Mundo: migración del campo a la ciudad, crecimiento urbano sin planificación, pauperización extrema, crisis de representación política y social, crisis económica.

El ensayo Lima la horrible (1964), de Sebastián Salazar Bondy, es una reflexión intensa y rigurosa sobre los cambios vertiginosos que viene experimentado la urbe peruana a mediados del siglo xx. En tan sólo sesenta años (de 1940 a 2000) la urbe pasó a tener de seiscientos mil habitantes a más de siete millones. Es menester pensar en los numerosos problemas de habilitación urbana que una ciudad como Lima experimentaba de cara a los desafíos de su modernización.

La llamada Generación del 50 de la literatura peruana ${ }^{5}$ observa estos cambios con fascinación, porque percibe a los nuevos sujetos sociales que emergen en la urbe, pero también con preocupación, porque los sistemas de castas dispuestos por la oligarquía dominante impiden una integración real del país. ${ }^{6}$ Lima, por ende, encabeza una “modernidad epidérmica” (Valero Juan 122): “La ciudad, por fin descrita en su integridad [por la Generación del 50], y como imagen de la realidad nacional, muestra a partir de ese momento las contradicciones que se derivan de un proceso modernizador aplicado

5 En su nómina figuran autores como Carlos Eduardo Zavaleta, Enrique Congrains Martin, Oswaldo Reynoso, Eleodoro Vargas Vicuña, Luis Loayza y los más representativos: Sebastián Salazar Bondy, Julio Ramón Ribeyro y Mario Vargas Llosa. Esta generación asimila las técnicas modernas de narración (vía Faulkner y Joyce) y el ambiente de sus narraciones tiene como escenario fundamental la urbe, en contraposición al indigenismo de las décadas anteriores.

6 Tendrán que pasar muchos años, hasta la década de 1990, para que esta situación comience a variar y sea el mercado el que comience a integrar la economía informal en un sistema más horizontal de distribución de bienes y servicios. Para un análisis de la informalidad en el Perú puede verse el libro de DeSoto, El otro sendero.

Revista Iberoamericana, Vol. LXXVIII, Núms. 238-239, Enero-Junio 2012, $147-161$
ISSN 0034-9631 (Impreso) 
sobre las bases de una sociedad tradicional y adormecida” (203). Las contradicciones ya han sido evidenciadas por esta nueva narrativa, pero llegan a su punto culminante en las imágenes de Lima la horrible:

La city se ha erigido con pobres imitaciones de rascacielos, pero rumbo al Pacífico han surgido barrios populosos (La Victoria, Breña, Lince) y, más cerca al mar, barrios residenciales (San Isidro, Miraflores, Monterrico), todos de caótica arquitectura donde el tudor y el neocolonial se codean con el contemporáneo calcado, salvo excepciones de magazines norteamericanos. Clase media y burguesía grande se sitúan en estas dos clases de barrios fronterizos. La masa popular se hacina, en cambio, en tres espacios de horror: el callejón, largo pasadizo flanqueado de tugurios misérrimos; la barriada, urbanización clandestina y espontánea de chozas de estera que excepcionalmente deriva en casita de adobe o ladrillo, y el corralón, conjunto de habitaciones rústicas en baldíos cercados. (Salazar Bondy 49)

La segmentación geográfica en distritos, en la medida de su proximidad o distancia del centro de Lima, marca las diferencias sociales, de comportamiento y rango de sus habitantes. Se es más rico o pudiente en la medida que nos alejamos más del centro y sus tugurios, ${ }^{7}$ casi siempre en dirección al sur de la ciudad. ${ }^{8}$ En la década de 1960 vivir en tal o cual distrito de Lima marca la posición en el espectro social y, en muchos casos, los destinos personales. La caracterización de la pobreza también es explícita y da cuenta del fracaso de la modernización de la ciudad; por consiguiente, del de la utopía republicana del siglo XIX. O mejor dicho: gracias a la modernización han aparecido el callejón, la barriada y el corralón. Serán estos espacios que, desbordados por la presión demográfica, se convierten en el rostro palpitante y demandante de la urbe en los años siguientes a la publicación de Lima la horrible.

\section{EXTRAPOLACIONES LIMEÑAS}

Y si bien la Generación del 50 patentizó los dramas presentes de una ciudad como Lima, José B. Adolph en la novela Mañana, las ratas lleva a sus últimas instancias el

\footnotetext{
7 Nótese, por ejemplo, la misma segmentación en novelas como La ciudad y los perros (1962), de Mario Vargas Llosa. Las familias "decentes" y la juventud bon vivant de la clase media vive en distritos cercanos al mar, como Miraflores o Barranco; mientras que la clases bajas se desplazan por zonas más deterioradas como el centro de Lima, Lince y el Callao. La Victoria es el distrito asociado a los burdeles y la delincuencia.

8 Las clases pudientes en Lima han migrado hacia el sur de la ciudad con mayor frecuencia en los últimos años, siguiendo la ruta de las playas al sur de Lima. Una de estas playas, Asia, un antiguo asentamiento de campesinos, experimentó un boom urbanístico a fines de la década de 1990. Actualmente es el lugar de veraneo por definición de las elites limeñas. En la novela, la familia de Tony Tréveris vive en una de estas playas sureñas.
}

Revista Iberoamericana, Vol. LXXVIII, Núms. 238-239, Enero-Junio 2012, $147-161$
ISSN 0034-9631 (Impreso) 
llamado de alerta sobre la ciudad. Honores resume algunas características de la urbe limeña en el año 2034:

La ciudad de Lima, con más de 20 millones de habitantes (oficialmente, 15 millones), ha crecido hacia sus “conos”9 (Mala, Pucusana, Huacho, Ancón, Surco) y está habitada principalmente por los excluidos, las "ratas", cuya existencia evidencia una diferencia dentro de la estructura social. En el centro de Lima, habitan también “enfermos mentales agresivos” (9). Es decir, “locos” y “agitadores políticos” conviven en un mismo espacio. La insania se ha normalizado. No sorprende, entonces, que no exista una conciencia inicial de la magnitud de la rebelión. En vista de la cotidianidad de la violencia, las casas son amuralladas y electrificadas, además de tener guardias privados vigilantes con: "uniforme kaki, casco transparente hasta los hombros, como los astronautas del siglo pasado, pistola ametralladora y minilanzallamas, botas negras”(13); los automóviles están equipados con armamento, además de un sistema de autolimpieza de sangre, para las "ratas" que cruzaran la pista "sin hacer uso de los puentes” (16), o lugares prohibidos, y cuyo atropellamiento es totalmente legal. Esto es, la tecnología (y las leyes) no ha servido necesariamente para integrar a los sujetos, sino para marcar aún más sus diferencias, pues el "progreso” es siempre para unos pocos. (“El sujeto”)

Podemos sostener, entonces, que Mañana, las ratas es una extrapolación de la visión que sobre Lima traza el ensayo de Salazar Bondy. Lo curioso del caso es que, por ejemplo, las murallas electrificadas y los guardianes privados aluden a los cambios experimentados en Lima de fines de los setenta y principios de los ochenta, con su desenfrenado crecimiento demográfico, pero sin otorgar mejores condiciones de vida a sus habitantes.

Asimismo, y como señala Honores, la violencia se ha hecho cotidiana por la situación del país en esos años. El surgimiento del terrorismo en 1980 con Sendero Luminoso y la respuesta militar del Estado obligaron a los ciudadanos a encerrarse en sus casas y contratar servicios privados de vigilancia, aunque sin el sofisticado armamento que Adolph les confiere en la ficción. En una escena de la novela, las fuerzas del Directorio Regional bombardean la antigua zona residencial de Miraflores, bajo control de los cat-ox. Este suceso ficcional prefigura, en la vida real, el atentado de la calle Tarata en 1992. ${ }^{10}$ Así, el escritor ha proyectado las condiciones del presente en que se escribió la

9 Los conos obedecen a los puntos cardinales de la ciudad (Norte, Este y Sur). Mala y Pucusana están en el sur de la ciudad, casi pegadas al mar; Huacho y Ancón al norte; y Surco hacia el este. Si bien la urbanización de estos conos se inició a la manera de la barriada, en nuestros días son los ámbitos de mayor desenvolvimiento económico de la ciudad. Una enorme masa de consumidores pasa el tiempo en modernos malls, hoteles, complejos cinematográficos, restaurantes de comida rápida, discotecas y locales de música tropical andina, acorde con la sensibilidad y los gustos de estos nuevos actores sociales.

${ }^{10}$ El atentado (la explosión de un coche bomba) fue cometido por miembros de Sendero Luminoso el 16 de julio de 1992 en una calle de Miraflores, zona de clase media y alta limeña. En ese momento la población

\footnotetext{
(3) Revista Iberoamericana, Vol. LXXVIII, Núms. 238-239, Enero-Junio 2012, 147-161 ISSN 0034-9631 (Impreso) ISSN 2154-4794 (Electrónico)
} 
novela. Cano indica que la extrapolación o técnica de construcción de mundos posibles, "proyectados hacia el pasado o el futuro", utiliza como referencias las condiciones predominantes en la realidad contemporánea a la escritura del relato (261).

UTOPÍAS CORPORATIVAS, REALIDADES DISTÓPICAS

Alimentado por la visión crítica de la urbe y el país en Lima la horrible, que se hacen evidentes en los años de escritura de la novela, Adolph inventa una ciudad pavorosa, cuya realidad marginal es conscientemente soslayada por la élite dominante. Para el lector, la novela opera en territorios cognoscibles, pero a la vez, lo fantasmal de la representación se basa en la "desfamiliarización” que caracteriza a todo discurso distópico. En ese sentido, la novela recurre a la estrategia de los cruces temporales entre el pasado del relato y su presente. Compruébese con la mirada de Tréveris sobre el antiguo casco urbano de la ciudad:

Siempre le producía el mismo shock de melancolía rabiosa el cruce de lo que, en su niñez, todavía insistía en considerarse el centro de Lima. Curiosamente, ahora lo era más que antes, geográficamente hablando. Ya alrededor del año 2000, cuando Tony tenía once años, lo que en tiempos se había llamado el cuadrado o damero de Pizarro, la Lima de los fundadores, era un turbio hacinamiento del cual solamente podían recorrerse sin mucho problema las avenidas anchas. [...] También el nuevo centro Miraflores había seguido, poco después, el mismo camino: altos edificios, orgullosos en su estreno, construidos en calles angostas, ahora mantenían en la sombra permanente, como esas callejas en torno a Wall Street, en Nueva York, a un mundo muy diferente al que desplazaron en la segunda mitad del siglo veinte. Pero era el centro de Lima lo que, de alguna manera, le afectaba más, quizás porque su padre y sus abuelos le habían relatado su historia, su belleza, su encanto "quizás falsos o sobredimensionados” con mayor gracia que la de los ojos de Tony y su relación con Miraflores. (Adolph 17)

Es sintomático que la novela se inicie con un recordatorio de la fundación de Lima, ${ }^{11}$ que en este pasaje Tony Tréveris evoca indirectamente. Es una fecha que en 2034 ya no tiene importancia para nadie o la tiene para muy pocos. La situación política y social del Perú ha cambiado por completo. Lima es sólo la capital administrativa de la Región Sudamérica-Oeste en una era en la que los Estados-nación han desaparecido y han sido absorbidos por grandes corporaciones internacionales, en este caso Stimudrinks, en la ficción de Adolph. Lo gubernamental se remite a las decisiones tomadas por los directorios regionales, sustentados por tecnocracia local, a la cual Tréveris pertenece.

limeña se tomó conciencia que el conflicto armado interno, con doce años de dolor y muerte en la zona andina central del país, había llegado a la capital.

11 Ver nota 2.

Revista Iberoamericana, Vol. LXXVIII, Núms. 238-239, Enero-Junio 2012, $147-161$
ISSN 0034-9631 (Impreso) 
Esta situación se explica en el diálogo entre Tréveris y un piloto del directorio, ante la amenaza de insurgencia de las ratas:

\begin{abstract}
-Un día el Directorio se va a despertar más frutado que esos guardias y con un gobierno de ratas [-dice el piloto].

-No exageres, hijo. El Directorio es inderrocable. No es como los gobiernos de antes. ¿Sabes por qué caían los gobiernos nacionales? Te lo voy a decir: porque antes había política. ¿Y qué es la política? Relaciones de poder no comerciales, irrazonables, basadas en el contacto entre las gentes y en ideologías.

-Mi padre me habló del gobierno. Del último, antes de la confederación mundial. Era un caos.

-Así es. El internacionalismo democrático-comercial nos salvó de lo peor. Esto es una maravilla comparado con lo que tendríamos si no se hubiese eliminado el estadonación. Eso lo sabemos desde el colegio. Y fíjate que cuando yo iba a la escuela, esta región todavía era una república más o menos independiente. Lo único que se ha hecho es eliminar la hipocresía: el Directorio, nuestro gobierno regional, es el primer gobierno sincero de la historia. Por primera vez coinciden el poder económico y el político abiertamente, como debe ser. Quien sabe manejar una empresa, sabe manejar una región. (Adolph 29-30)
\end{abstract}

Esta extrapolación del presente hacia el futuro hace realidad y hace visible la idea del progreso fundamentada en lo monetario: transacciones comerciales antes que ideologías. La última utopía de la que habla Adolph no es la experiencia comunista ni socialista, sino más bien el paraíso del capitalismo triunfante sobre las anquilosadas estructuras del Estado-nación. En el caso latinoamericano esta utopía como programa político y económico tiene un nombre claro: neoliberalismo. La desregulación del Estado de bienestar es su objetivo, y es probable que hasta su eliminación. Al menos, en el año 2034, ha conseguido estas metas con el apoyo de los tecnócratas locales.

De este modo, con la instauración del Directorio, la forma política del neoliberalismo elevado a la máxima potencia se ha eliminado la hipocresía y el disimulo que regían las antiguas relaciones del Estado moderno. Lo público y lo privado ya no ofrecen matices y sutilezas. Las prácticas sexuales abiertas ya no son objeto de condena moral, al contrario, se fomentan e incentivan. Más bien, la fidelidad es sospechosa de ser asociada con los cat-ox (25). A ello se refiere Tréveris con la "sinceridad" del Directorio: al no haber privacidad, se hace mucho más sencillo el control social.

La pregunta, aquí, es: dado que se ha implantado la utopía capitalista como máximo logro de la historia -y aquí la ficción de Adolph es una curiosa precursora de los teóricos del "fin de la historia" de los años noventa, como el politólogo Francis Fukuyama, entre otros- ¿por qué ha permitido la existencia de un cuerpo social ajeno al sistema? Porque, en todo caso, si se comporta como el gobierno más "sincero", debió haber sido igual de sincero con los desposeídos; no obstante, los extermina. La existencia de las "ratas"

Revista Iberoamericana, Vol. LXXVIII, Núms. 238-239, Enero-Junio 2012, $147-161$
ISSN 0034-9631 (Impreso) 
es el hoyo que articula el sistema entero. Si tomamos la terminología lacaniana, es el exceso de real que articula el orden simbólico implantado por el Directorio Supremo. Linda King y Tréveris presencian este exceso de lo real durante uno de sus primeras excursiones por la ciudad.

\begin{abstract}
Por la calle, a pleno sol del mediodía, avanzaba una horrible procesión: bajo una tosca cruz de madera, se arrastraban hacia ellos decenas, quizás centenas de niños lisiados, pálidos y sucios, murmurando una jerga incomprensible. Los ojos de Tony y de Linda reflejaron el horror de esas criaturas débiles y harapientas, guiadas por un sacerdote de hábito negro, que les hacía avanzar restallando un látigo que se cebaba en las espaldas de los niños y niñas más cercanos a él.
\end{abstract}

Tony Tréveris y Linda King volvieron a la realidad (86).

La utopía corporativa del Directorio -y, en líneas generales, del capitalismo, ya que el Directorio es su manifestación más avanzada- no ha hecho más que alimentar a los más ricos y empobrecer a los más pobres. Buena parte de las ficciones distópicas del siglo xx han sostenido que la aplicación radical de este modelo conduce a un ámbito de dicotomías. Phyllis J. Day señala, a propósito de un ejemplo de estratificación social:

In Realms of Tartarus (1977), [Brian] Stableford gives us a powerful statement on social stratification and racism with a depiction of a two-level society. "Heaven" -a platform built over the surface of the earth- is inhabited by an elite society. These people are content with their lives and have forgotten that people still exist below, in "Hell”. There, in an environment denied the light of the sun, evolution speeded by survival needs and pollution from Heaven has diversified the human species. (196-97)

En efecto, la dicotomía entre “cielo” e “infierno” puede aplicarse a la sociedad de “dos niveles” configurada por la utopía corporativa de Mañana, las ratas. Sólo que en el caso latinoamericano el capitalismo ha potenciado las condiciones que describe y critica Lima la horrible. Fomentado por el libre mercado, estamos inmersos en un entorno en el que predomina el darwinismo social, la división de la humanidad en dos especies diferenciadas, los aptos para la evolución y los que están fuera. La radicalidad de este darwinismo no hubiera sido posible sin entornos coloniales previos, donde la discriminación y la segmentación en castas sociales eran y son moneda corriente.

Después de todo, el Directorio es otra manifestación de la presencia imperial, sólo que se disfraza de local en función de sus intereses corporativos, en alianza con las oligarquías locales, representadas por sus herederos, los tecnócratas. En la novela, Stimudrinks tiene su fachada local: Empresa de Productos Estimulantes, Sociedad Anónima (mejor conocida por sus siglas, EPESA) y en ella las decisiones políticas se

\footnotetext{
Revista Iberoamericana, Vol. LXXVIII, Núms. 238-239, Enero-Junio 2012, 147-161 ISSN 0034-9631 (Impreso) 
toman en función de su eficiencia, a fin de perennizar la dominación conformista de la elite: "The goal of such control in science fiction is to insure conformity, which maintains a status quo to benefit an elite group. The same goals exists in our reality” (Day 199).

El giro distópico, el despertar del sueño utópico a la dureza de la realidad, ocurre cuando las intenciones de King se revelan a los ojos de Tréveris. Las grandes computadoras del Directorio Supremo, las verdaderas regentas del sistema-sistema al cual el Cardenal Negro se refiere irónicamente como "capitalismo cibernético" (Adolph 129)-, han determinado que el Directorio regional sea derrocado por los cat-ox:

El Directorio Supremo deseaba saber cuál es su poder real y si se puede llegar a un acuerdo con ellos. La respuesta que les llevo coincide exactamente con el análisis situacional que nos habían dado las computadoras de California. El régimen, aquí en Sudamérica Oeste y probablemente en otras regiones, se ha dejado aislar demasiado de la realidad. Su ceguera, su indiferente prepotencia, su desvinculación con la sociedad que dice administrar alcanzan un factor superior al 90 por ciento. Y en cuanto a un arreglo con los cat-ox, la respuesta es igualmente positiva. No es nuestro ideal, ni mucho menos, pero lo que nos interesa fundamentalmente no es enamorarnos de quienes administran el Tercer Mundo, sino que se mantenga la relación de fuerzas internacional y el sistema a nivel mundial. (141)

Si en la conversación con el piloto Tréveris aseguraba que el Directorio era "inderrocable", pues no estaba lejos de una verdad entre las apariencias: sólo el propio Directorio es capaz de derrocarse a símismo, a fin de sobrevivir. Es una lógica que obedece al mismo movimiento del capitalismo: generar una crisis que altere las estructuras de poder, a fin de seguir manteniendo el dominio y el equilibrio. ${ }^{12}$ Esta revelación genera una sensación de no pertenencia en Tréveris, de descreimiento e irrealidad:

Mi gente me ha traicionado, y mis enemigos no son, realmente, enemigos. [...] comienzo a creer que soy un fantasma entre fantasmas. Estuve demasiado ocupado para soñar $\mathrm{y}$, apenas surge una posibilidad de hacerlo, descubro que todo es un inmenso sueño o que todo es una fría realidad blanca sin matices de ninguna clase, que viene a ser, en el fondo, exactamente lo mismo. (149)

Así, la proyección del yo como ideal (lo utópico) se ve socavada por fuerzas ajenas que revelan lo fútil de la mirada complaciente con la que solemos vernos a nosotros mismos. Detrás de las fantasías se esconde una realidad "blanca” y en ella el sujeto

12 El antagonista del Directorio Supremo de Occidente es el imperio marxiano-confuciano de Oriente (51) o los “Asiáticos”. Adolph prefigura alegóricamente el rol de China como nueva potencia mundial en el siglo xxI.

Revista Iberoamericana, Vol. LXXVIII, Núms. 238-239, Enero-Junio 2012, $147-161$
ISSN 0034-9631 (Impreso) 
está desplazado, sólo ocupa un lugar accesorio o, en el peor de los casos, instrumental en medio de esa inmutabilidad.

El despertar de Tony Tréveris será duro. Linda, él y su familia alcanzan la cúspide de la pirámide social: las grandes estaciones espaciales donde se refugia el Directorio Supremo, en evidente actitud evasiva con la nueva correlación de poderes. Sin embargo, no será fácil para los protagonistas escapar del afán de revancha de los insurgentes. Como sugiere el final de la novela, los antagonismos sociales no concluyen hasta que se aniquila la base misma del antagonismo. Y, dado que nos encontramos en el siglo xxi, los recursos tecnológicos están altamente disponibles, incluso para sectas ultraconservadoras como los cat-ox.

\section{CONCLUSIONES}

En Mañana, las ratas encontramos una visión desesperanzada de la historia. La naturaleza distópica de su narración nos conduce por una revisión del pasado cercano, en relación con una modernidad periférica: Perú. Por los distintos niveles de discurso que maneja, consideramos este texto de anticipación como una de las pocas novelas de ideas que se escribieron en el Perú a fines del siglo xx.

Llama la atención cómo Adolph utiliza este texto para tratar diversos hechos que han marcado la sensibilidad contemporánea. En el caso peruano, visualizó el estado de la violencia política ${ }^{13}$ en su momento como una suerte de lucha entre dos extremos: el capitalismo avanzado y el fundamentalismo (de índole religiosa en el caso ficcional).

Por otro lado, Adolph también prefigura un nuevo orden mundial geopolítico, aspecto sobre el cual ha seguido explorando en otras novelas y relatos posteriores. La historia, la filosofía y la política son numerosos ámbitos sobre los cuales se desplaza con naturalidad la escritura de Adolph, aunque en el caso de Mañana, las ratas muchos diálogos se exceden un poco en la exposición de ideas. Ello, no obstante, no le quita mérito a la calidad narrativa y expositiva de la novela.

Es evidente la ruptura de Mañana, las ratas con la narrativa realista de su momento, pero creemos que no se ha incidido mucho en la relación que establece con otros textos literarios. Más bien, vale la pena destacar el nexo con el ensayo Lima la horrible, de Salazar Bondy, con lo cual se traza una continuidad con la representación de Lima en la literatura actual, línea inaugurada por la denominada Generación del 50.

Los lectores podrán encontrar en sus páginas, efectivamente, una Lima que se disuelve entre los distintos intentos modernizadores y las descripciones hostiles de un

${ }_{13}$ En el Perú, la violencia política duró desde 1980 hasta el año 2000, y abarca tres períodos gubernamentales: los de Fernando Belaúnde (1980-1985), Alan García (1985-1990) y Alberto Fujimori (1990-2000), y cobró más de setenta mil víctimas, la mayoría de ellos quechuahablantes, según el Informe Final de la Comisión de la Verdad y Reconciliación.

\footnotetext{
Revista Iberoamericana, Vol. LXXVIII, Núms. 238-239, Enero-Junio 2012, 147-161 ISSN 0034-9631 (Impreso) ISSN 2154-4794 (Electrónico)
} 
ambiente deshumanizado. Aquí percibimos su raigambre distópica en relación con la serie de poderes dominantes en su tiempo y que en esencia son los mismos hoy en día. Por ello la sensación de “desfamiliarización” que impregna sus páginas desde el inicio. Reconocemos los lugares, la ciudad, pero ésta también ha exacerbado sus problemas al punto del caos, haciéndola difícil de asir.

En ese sentido, su contribución a la formación de una ciencia ficción en América Latina es fundamental. En una entrevista, Adolph dice, refiriéndose al género: "Es el más profundo análisis de lo actual” (Stagnaro), es decir, la posibilidad de fabular mundos alternativos que presenten una visión crítica de nuestro presente, sobre todo en una actualidad marcada por la agenda de los discursos mediáticos que tiende a encubrir la verdad de acuerdo con intereses corporativos o políticos.

Creemos que es importante volver a Mañana, las ratas porque abre nuevos retos y desafíos a la narrativa peruana contemporánea. Sobre todo porque hace posible el debate de ideas, que es una de las intenciones de la narrativa de José B. Adolph: hacer pensar al lector. La edición de 1984 ya casi no circula en el Perú y es menester una reedición que coloque a esta novela en su verdadera dimensión, al alcance de los lectores. Entre los adeptos al género Adolph es un clásico. La idea es que siga hallando a sus lectores, que en estos momentos vienen inventando la historia del futuro.

\section{BiBLIOGRAFÍA}

Adolph, José B. Mañana las ratas. Lima: Mosca Azul y Cedep, 1984.

Basadre, Jorge. La promesa de la vida peruana y otros ensayos. Lima: J. Mejía Baca, 1958.

Beaumont, Matthew. "News from Nowhere and the Here and Now: Reification and the Representation of the Present in Utopian Fiction". Victorian Studies (Autumn 2004): 33-54.

Bernal Méndez, Christian y Penélope Villalonga Nattari. "Siglo y medio de silencio: una apertura para Lima de aquía a cien años (1843)”. Ajos y zafiros 7. dic. 2005. $<$ http://ajosyzafiros.erucultural.org.pe/textos/o7pant1.doc>. 23 sept. 2010.

Bonifaz Ureta, Carlos. "Del compilador”. Ur[b]es 3 (enero-dic. 2006): 269-70.

Booker, Keith M. The Dystopian Impulse in Modern Literature. Westport, CT: Greenwood Press, 1994.

Cano, Luis C. Intermitente recurrencia: la ciencia ficción y el canon literario hispanoamericano. Buenos Aires: Corregidor, 2006.

Comisión de la Verdad y Reconciliación. Informe Final. Lima: CVR, 2003. Disponible en internet: <http://cverdad.org.pe>.

Day, Phyllis J. "Love and the Technocracy. Dehumanization in Social Welfare". Clockwork Worlds. Mechanized enviroments in SF. Richard D. Erlich y Thomas P. Dunn, eds. Westport, CT: Greenwood Press, 1983. 195-211.

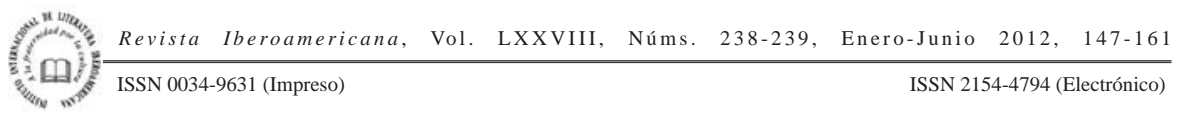


DeSoto, Hernando. El otro sendero: la revolución informal. Con contribución de Enrique Ghersi, Mario Ghibelli y el Instituto Libertad y Democracia. Pról. Mario Vargas Llosa. Lima: El Barranco, 1986.

De Vivanco, Lucero. “Apocalipsis (post-bicentenario) en la ciudad de Lima. Representaciones de la ‘modernidad' y la 'nación' en Mañana, las ratas de José B. Adolph”. Revista de Crítica Literaria Latinoamericana 36.71 (primer semestre 2010): 237-254.

Elguera, Christian. "Diálogo, historia y utopía: Lima de aquí a cien años como unidad y la idea de nación”. El Hablador. 16 mayo 2009. <http://www.elhablador.com/ est16_elguerat.html> 23 sept. 2010.

Fukuyama, Francis. The End of History and the Last Man. Nueva York: Free Press, 1992.

Honores, Elton. "El sujeto programado y la ciudad distópica en Mañana, las ratas”. El Hablador 15. 2008. <http://www.elhablador.com/est15_honores1.htm>. 23 sept. 2010.

Jameson, Fredric. "Progress versus Utopia; Or, Can We Imagine the Future?” Science Fiction Studies 9/2 (1982): 147-58.

“Mañana las ratas ... Lima la horrible del siglo XXI”. La República 26 de julio 1984. 25.

Moylan, Tom. Scraps of the Untainted Sky. Science fiction, utopia, dystopia. Boulder, CO: Westview Press, 2000.

Nevares, María Fe. "Mundo, demonio, Adolph". Caretas 21 junio 2001. <http:// caretas.com/pe/2001/1675/secciones/cultural.phtml>. 23 sept. 2010.

Portillo, Julián del. Lima de aquí a cien años [primera entrega]. El Comercio 1231 (30 junio 1843): 1-4.

"Cusco de aquí a cien años" [segunda entrega]. El Comercio 1236 (4 julio 1843): 3.

"Lima de aquí a cien años" [tercera entrega]. El Comercio 1241 (1 agosto 1843): 1-2.

“Lima de aquí a cien años” [cuarta entrega]. El Comercio 1242 (2 agosto 1843): $1-2$.

"Cusco de aquí a cien años" [quinta entrega]. El Comercio 1244 (4 agosto 1843): $1-2$

"Lima de aquí a cien años" [sexta entrega]. Lima: Imprenta de El Comercio, 1844.

Salazar Bondy, Sebastián. Lima la horrible. Lima: Peisa, 1973.

Stagnaro, Giancarlo. "Entrevista con José B. Adolph”. El Hablador 3. 2004. <http:// www.elhablador.com/adolph.htm>. 23 sept. 2010.

Valero Juan, Eva María. Lima en la tradición literaria del Perú: de la leyenda urbana a la disolución del mito. Lleida: Edicions de la Universitat de Lleida, 2003.

Revista Iberoamericana, Vol. LXXVIII, Núms. 238-239, Enero-Junio 2012, 147-161
ISSN 0034-9631 (Impreso) 
